\title{
Social Space and Its Varieties in Music: To the Problem of Archetypes
}

\author{
Svetlana Anatolyevna Mozgot \\ Valeriy Georgievich Mozgot
}

Federal State Budget Institution of Higher Professional Education «Adyghe State University» (ASU) 385000, Maikop, street Pervomayskaya, 208, Russian Federation; Email: nisadgu@yandex.ru

\section{Doi:10.5901/mjss.2015.v6n5s1p553}

\section{Abstract}

The problem of social space has been actively developed in philosophy, sociology, art history and related humanities from the end of XIX century, but still it has not been reflected adequately in the musicology. The purpose of this article is to demonstrate the existence of archetypes "intimate" and "personal" space as varieties of the social space as exemplified by musical works $X V I I-X X$ centuries, to identify their features in the music and determine the ways of expression. In science the archetype traditionally implies "patterns" of the collective unconscious. The concept of the archetype of in the form of "historical model" can be interpreted as a reflection of different social structures and their corresponding behaviors, in which a variety of spacetime representation, such as "intimate", "personal" space should be used. We have applied the methods of differential psychophysiology, proxemics, hermeneutics, epistemological method and musicological analysis in our work. As a result of the study the intimate space features in the music were established: modeling of human inner life processes. The ways of expression include a monologue-reflection and a monologue-self-reflection. The intimate space structure is characterized by inwardness, closedness, by the reproduction of features having the same volume. The personal space features in the music mean the presence of something unusual, ingenious in the "behavior" of a musical character. The ways of expression of the ingenious include departure from the usual genre and stylistic norms of the musical language of the epoch; the presence of various forms of dialogue; high extent of the energy message transmitted through the intensity of the experienced emotion directed to the outside world; thematization of the musical texture layers. The structure of personal space is open, discrete and depends on the behavior of the character and the events taking place in it expressed using an intonation contrast, a conflict. Clear differentiation of features of the different social spaces in the music simplifies their identification in the content of musical genres. It is through the character understanding that comprehension of the character's person in the history of the culture of a certain epoch and its reducing as a carrier of history of human communities transferred in the musical sound occurs.

Keywords: social space in music, models, image-bearing world of music музыки, archetypes, personal space.

\section{Introduction}

The concepts of differently dimensional social spaces went down in the history of science owing to the research of American anthropologist Edward T. Hall (1966), who introduced them to study communication processes occurring in the different communities. For the musical art the study of various types of space in the content of a piece of music comes at an opportune time, since the embodiment of various forms and types of communication is one of the aspects of the image-bearing content of music and, in addition, the music itself is a form of communication. The most studied subject of the music as a form of communication is revealed in the works of M.G. Aranovsky (1987), Ye.V. Nazaikinskyy (2003), G.A. Orlov (2005) and other authors from the external position - the interaction of elements in the triad "composer performer - listener". At the same time, studying figurative and semantic content and the means of expressing different models of social space in the music deserve particular attention, because all these varieties affect the dramaturgy, form and internal content of the music genre.

One of the major problems in the study of social space is the lack of a unified methodology and observed by us fragmentation of approaches to the study of this notion by the scientists from different fields of scientific knowledge. A.I. Pigaliov (2012) notes that the concept of "social space" is becoming more and more popular in the humanities and social sciences, but most frequently it is not detailed and not specified. E.V. Saiko (2012) points out that in the modern literature the social space is "... simplistically reduced to the public one (also assuming complex content, its special intrinsic characteristics)". It is noteworthy that the study of the concept of 'social space' in the philosophy started precisely in the context of understanding the social processes. Thus, Emile Durkheim believed that the category of space is especially social category, defined by human experience (cited by: Pigaliov, 2012). Nevertheless, initially the parameters of the 
physical space were directly projected onto the social space in the works of philosophers and sociologists of the XIX century. We know that the measurement of physical space takes place in the parameters: continuity/discontinuity; connected/separated; symmetry/asymmetry and others. However, in the course of the study it was found that for measuring the social space parameters other values are more adequate, for example, such as the 'social distance', 'social force', 'social dynamics', 'field' and so on, which allowed V.K. Potiomkin and A.L. Simanov (1990) to form the definition of 'social space'. By it the researchers mean "the space that is formed by social processes and interactions and in which these processes and interactions are implemented". Thus, with the introduction of these concepts in the science completely different nature of social space differing from the physical one was marked.

A special contribution to the development of the sphere of social space science was made by Kurt Lewin (2001) who introduced the concept of 'field' from physics and developed a theory of psychological field or psychological forces affecting the man. "Any object displays its properties in the interaction with other objects; therefore, the properties are the characteristic of the concrete interactions between the objects. The field has its own topology, the areas separated by borders of varying degrees of rigidity and a certain dynamics of forces affecting the individual present in this field, which may vary considerably at various points in this field are distinguished in it. Thus, the behavior appears as a function of the specific constellation of the field forces generating in the individual the tension of the system that tends to its discharge" (Lewin, 2001).

The designated lines of research of social space forced the scientists to conclude that the "social space exists not in the physical and geographical space, but against the background of physical and geographical spaces acting as external prerequisite" (Potiomkin and Simanov, 1990). Studying the properties of social space has shown that "without analyzing the categories of communication and relationships it is impossible to understand the essence of space", its structural properties (Potiomkin and Simanov, 1990). The conclusion that the social space is a mobile structure conditioned by the fact that "social relations, changing in the development process, determine the specificity of social space" has also proved obvious (Potiomkin and Simanov, 1990). Thus, the structure of social space appeared to be directly related to the objects defining it.

In our research, the notion of 'social space' is used in two meanings. In the broadest sense it is the modeling of social processes and various situations of interaction between people in the music. In the narrow sense, the social space refers to specific models of human relations, embodied in the archetypes of the 'intimate' (Mozgot, 2011) and the 'personal' space (Mozgot, 2013) in the music.

In this aspect our understanding of the term 'archetype' is based on the provisions of Carl Jung's theory (1997). The scientist considered them to be not innate ideas, but innate possibilities of behavior which, in turn, are the cause for appearing the corresponding visual images. They can vary in detail without losing their basic pattern. Archetypes are instinctive trends of adaptive behavior manifested in the conscious fantasies and unconscious symbolic images. In our opinion, since the archetype also indirectly reflects the different social structures and behavior models associated with them, we believe that their representations are to be used as diverse spatio-temporal structures, such as 'intimate' and 'private' space.

\section{Methods}

To comprehend the concepts of other sciences, such as the 'character', 'hero', 'monologue', 'dialogue' and find out their specificity with respect to the piece of music the epistemological method is used. The differential psychophysiology methods developed by E.A. Golubeva (2005) and a group of psychologists are involved to clarify psychophysiological differences in the concepts of the 'individual', 'personality', 'individuality'. Appeal to the method of measuring proxemics (from the English 'proximity' - nearness) developed by E. Hall (1968) helps identify psychological and topographic differences of the spaces formed during communication of various groups and communities of people. The application of the hermeneutic method is determined by the need to interpret features of varieties of space in terms of their imagery and semantic content in a musical composition. The musicological analysis method allows finding ways of expressing intimate and personal spaces in the music.

\section{Results}

The study of the 'intimate', 'personal' space or the personality's space in the music requires the introduction of terms, enabling to define the actor in the music - the musical character, the hero of a musical piece. According to Ye.V. Nazaikinskyy (2003), " purely musical formations - melody, theme, textural pattern, original sound of the instrument $\langle\ldots\rangle$, any actual musical figure that can play this or that role in the theater of pure music - become the characters of 
instrumental pieces". The scientist shows a musical character from the position of its reflection in the musical language. V.V. Medushevskyy (1976) and V.I. Nemkovskaya (1998) underline the psychological component in the musical character, seeing it as a nature expressed through the intonation. O.A. Osipenko (2010) deepens this trend, assuming that the nature of the musical character affects the manner of his behavior, gait, plastics, gestures conveyed by means of musical intoning, as well. Thus, we understand that the intoning forming a tonal relief is one of the leading features inherent in the embodiment of the musical character in the piece of music. It is created by various combinations of musical expression means - rhythm, timbre, register, orientation of the melody intervals, harmony, texture, articulation and others. But the space-time position is the most important in the characteristic of the musical character, since it precisely reveals the functions of this character in the content of a piece of music as the main character, supporting character, the extras.

Features enabling to bring the musical character into the category of the hero of a musical piece:

relief thematic invention, musical theme created by complex of expression means up to and including the introduction of the musical mark providing rememberability and recognizability of the hero;

detailization of the personal characteristics of the hero through the disclosure of his inner world, nature;

detailization of the personal characteristics through the description of personal space and his interaction with the outside world;

long-term stay in the limelight.

In this context the notion of a musical character applies to any subject acting in the content of a piece of music having the intonational vividness and sometimes coming to the limelight. By the term 'hero' we mean the subject defined by the musical theme, approving his 'life' position in the content of the musical work, staying in the limelight for a long time and influencing the events in the figurative and artistic world of the musical piece.

The musical science distinguishes two types of characters in the music: portrait and plot personages. The portrait type of incarnation of the musical character is created when the special features are "looming" and generalization occurs through a "detail" (Nemkovskaya, 1998), that is, the author opens to the listener such properties of the nature that cannot be seen immediately, but recognized in a deeper, long-term communication. As a rule, this intonational vividness develops into something more - a musical theme revealing thus the intimate space, forming three-dimensional characterization of the hero.

Another type of musical character, according to V.I. Nemkovskaya (1998), is a plot personage, in which the human existence is modelled in the world of the "others". There also personal characteristics of the musical character are enriched through the long-term observation of his actions in a changing context - in dealing with people and attitude to people, in description of their attitude to him, in modeling a variety of life situations. As opposed to the portrait-type character the plot-type personage creates a personal space in the music by recreating the pattern of his life activities.

We suggest a hypothesis that the represented varieties of the space (intimate and personal ones) form imagebearing sphere of the main character in the music, the personality's space. As exemplified by the works of Wolfgang Mozart, Ludwig van Beethoven, Frederik Chopin, Claude Debussy we shall try to identify the features that embody an intimate and personal space in the music, and consider means of expression creating characteristic qualities and recognizability of these spaces in the aural art.

\subsection{The intimate space.}

Initially, it is necessary to distinguish between very close at first glance, notions of an intimate and a personal space. According to $\mathrm{E}$. Hall, the personal space is a space of human comfort zone. It is viewed by the scientist as an individual physical interval defined by the boundaries of life imagined by a person in the said environment and evaluated by the person as a private area or territory (Hall, 1966). However, in the psychology clear boundaries are set out that allow separating the intimate space from the personal and social spaces. Intimate (from Latin 'intimus' - the deepest, inner) means deeply personal, privy, innermost; soulful. In the intimate space (with radius from 0 to $45 \mathrm{~cm}$ ) the closest people communicate: a husband and wife, mother and child (Reber, 2001). Personal space, according to E. Hall, is a dynamic category, since it depends on a very wide range of phenomena: the environment, cultural level, occupation, membership of a particular social class, and also ethnic stereotypes. We believe that E. Holl interprets personal space rather widely, including in it characteristics of the intimate space, as well, but the latter deserves a separate in-depth analysis, including as a category of proxemics. Immersion of the musical character in the intimate space is accompanied by inwardness, closedness of the latter, reproduction and observance of features of similar volume. Here the theme of the interaction of man with himself dominates, expressed in the concept of Innerlichkeit (from German) - inwardness. Self-inwardness in music is expressed in modeling such processes as reflection, remembering, emotional experience and peculiarities of 
speech flow as a means of person's self-expression. Another feature of the hero's withdrawal in the intimate space becomes the appearance of the inner monologue-reflection, a monologue-self-reflection. Lack of "voiced" questions that are posed by the hero for himself and that can be heard during the traditional monologue allows us to attribute a monologue to the category of the inner one. This monologue takes place in the personality's inner space between - using the terminology of Karen Horney (1997) - the idealized and the real images of 'self'. The listener comprehends only answers-reflections or the musical hero's feelings about ideas, events, and images disturbing him.

Each of these varieties of inner monologue has a number of features that organize the musical space. Thus, the intimate space, formed with the help of a monologue-reflection in the first part of F. Chopin's Nocturne in c-moll op. 48 No. 1 features in the following. It is characterized by stability associated with the representation of one psychophysiological state - cogitativity modeled using voice intonations in the music; discontinuity corresponding to the formation of mental structures; logical nature of structuring conditioned by an orderly process of thinking; differentiated relief and background together with consistency of textured execution; density of event-semantic content, which depends on the intonational value of each turn of the melody; horizontal direction of movement forward and its occurrence in real time "here and now".

The intimate space formed by the inner monologue-self-reflection, in the middle part of Nocturne b-moll op. 9 No.1 by Chopin, has clearly expressed features of the past time and experiences of the events that had happened once. They include "intonational vagueness, ornamental veiling of intonation nucleus with the common forms of motion; variation in intonation, unexpected harmonic and tonal turns, returns to the already sounded" et al. (these features were proposed and described in detail by L.P. Kazantseva, 2009). The consistency of one volume and one figural type of the texture is inherent in the intimate space created in the middle part of the nocturne using the monologue-self-reflection, which is due to the immersion in one emotional state. The intimate space is distinguished by weak structuredness depending on the modelled features of the recall process - repetitions, whirling in place, return to the already passed, absence of the culminating point; the circular nature of the movement arising from the concentration on a single image (or thought). Constant recollection of details leads to the dominance of the expositional type of presentation, which determines the statics of the movement in this space, as well as to the low semantic density, because the movement depends rather on the changes in emotion, the tonus of which is usually unidirectional and unchangeable than on the cause-effect relationships. Combination of all of these factors results in an overall asymmetry of the middle part structure.

\subsection{The personal space.}

In contrast to the intimate space, the personal space embodied in the music has an open structure formed because of the person's desire to influence the outside world. The psychologists associate manifestations of the personal space with the embodiment of the human personality. Whereas the description of the processes of human life described by conveying the character of the proceeding emotion, processes of thinking, speech peculiarities become the features of withdrawal into the intimate space, the personal space is associated with the modeling of human activities, where its interests (motivations or intensions); temperament (emotionality); ability (activity); character (self-regulation/will) are recognized (Golubev, 2005). The personal space in psychology makes from 45 to $120 \mathrm{~cm}$ and is used in everyday communication with familiar people (Hall, 1966). Accordingly, the figurative-semantic sphere of the personal space includes a reflection of the manner of the character's interaction with other people at the level of "I - You", "I - we", "My world - a different world".

The personal space of the personality is open to the outside world and depends on the interaction with it. The desire to influence the surrounding environment is revealed in the music in intonational distinctness, thematic specialness that distinguishes the hero from the surrounding musical material. Often this is done by expressive tone of the utterance, energetic message directed to the outside world in order to induce consent or sympathy with the hero's own position, to attract attention. Thus pathos of rhetorical speech addressed into the external world fills the primary arias of the first part of Beethoven's Sonatas No. 1, 8, 23. The orientation of the personality to the socium is typical of the works, the theme of which is related to the description of historical situations, dramatic social phenomena and problematic life situations that require choice or decision-making.

Formation of the personal space with the enumerated above features began with fixing the unconventional 'behavior' of a musical character. An example of such personal space created with the help of musical expressiveness mark we see in the second part of the V.A. Mozart's sonata No. 8 a-moll K 310. The intimate, chamber, cozy space of music theme is measured with calm flow of time, which is shown with a special sign - the individual 'solutions' of cadences. Cadence is a regulated and traditional part of the form, which resembles a polite nod; it is represented by Mozart in different ways. The musical character never comes to resolving by a beaten path in the development of the theme of the second part. He approaches it stealthily, either through gruppetto combined with the trill, or through moving 
away the desired resolution by including additional harmonies in the developing middle part, owing to the sophistication of the melodic line in the reprise.

Such a number of the unconventional emphasizes the playful wit as the lead quality of the musical character's individuality affecting the space organization. The composer is trying to overcome the 'attraction' of squareness and symmetry by cadence solutions, offering the direct dependence of the space organization on the subject's 'activity'. V.N. Kholopova (2010) notes that the classics had developed the richest arsenal of comic tools in the instrumental genres, including the articulation, pauses, contrasting change of dynamics. Whereas Mozart implemented a radical harmonic breaking in the comic purposes.

Nocturne F-dur op. 15 No. 1 by Chopin, in which the characters are revealed not through their behavior, but through the nature of their speech, is interesting from this perspective. In the first part of the nocturne a typical landscape space appears that is incarnated by leisurely ternary movement, calm melody reversal in the second octave, the repeated process, the total statics and harmony of the artistic image. All of the above means and method of recreating the reality match the lyrical description of the landscape, which is confirmed by the author's remark smorzando (from Italian 'growing slower and softer, dying away'), fixing the time of distancing. In the middle part there is a 'modulation' of the landscape space into the personal space of the hero-author. The expository type of material presentation, based on repetition and variation, is opposed to the evolving type. The tonality changes into the parallel minor, there appears a remark con fuoco (from Italian 'with fire, impetuously, passionately'), and slowly unfolding lyrical monologue of the first part turns into a dialogue in the middle part. Strong-willed, energetic flow of the semiquavers on $\boldsymbol{f}$ and short affirmative phrases in the dotted rhythm of the low register are opposed to the phrases on ff of the upper register, resembling heroine's speech. However, the hero's statements that have just been heard are repeated in these phrases. This allows suggesting that the heroine is vigorously supporting the hero's thoughts, and the personal space is formed by means of an emotional dialogue-agreement. The middle part is characterized by repetition of intonations with intense harmonic motion, which is expressed in the appearance of a chain of deviations. This resembles an energetic repetition of the ideas, which are important for the hero and with which he is trying to influence the world around him. Emotionality of the fragment may indicate that the feelings of the author and of the lyrical hero are assonant, similar, and here we hear the statement of Frederik Chopin himself on behalf of the hero.

The recapitulation repeats the first part, and due to this repetition, after so bright a dialogue it becomes clear that Chopin imagined a woman image both in the first part, and the reprise inscribed the picture of the surrounding landscape. This is indicated by the signs of human speech, and moreover on behalf of a lady: the register of the second octave, where the melody is deliberately placed in order to emphasize the fragility and tenderness of the image; a small length of phrases associated with specific human breathing while walking; a hidden dancing manner and grace of ternary meter; smooth movement of the accompaniment triplets, soft, rounded draping of phrase endings. The feminine element of the image is also emphasized by the author's remarks dolcissimo, delicatissimo. However, the listener learns that the female image description is recreated at the beginning of the play only in the reprise, by comparing the of events and differences of the heroes' spatial characteristics.

In general, F. Chopin succeeded to recreate the image of a secular promenade in the music where the hero found a like-minded person entered into his personal space in the middle part. This space turned out to be a closed ring, which is emphasized by the tonal movement (from $f$-moll, $b$-moll to $b$-moll and $F$-dur), as if accenting the focus on one idea. This space is logically organized and symmetrically structured, since it is a repeated period in the shape. Not always such spatial characteristics will be maintained during the formation of the personal space sphere in the music. Nevertheless, the technique of (horizontal) matching of the various spaces found by F. Chopin will be used in the music of the early twentieth century.

This can be exemplified by the embodiment of the behavior and character of Undine, implemented with the help of diverse timbre and textural complex of Claude Debussy's same name prelude. The personal space of this fantastic female character is formed by separating layers of texture with articulation. The composer connects simultaneously three layers of texture, depicting a multifaceted artistic image of playfully whimsical mermaid, inscribed in the landscape space of aquatic environment - the element of her life. The lower level - sustained sound A1 performed as legato, is a background, symbolizing the depth, massive water nature [t. 1]; consonance on staccato tied by the glide, remind water splashes and create the middle ground [t.t.1-3]; figurations of semiquavers in the second octave on legato, owing to its sound pictorialism, painting sparkling sprays [t.t. 4-7].

Articulatory division into layers is used by C. Debussy in the decorative sense, which, however, allows reproducing the character and features of Undine's behavior. This is one of the examples where the vertical synchronization of the personal and landscape spaces occurs. 


\section{Summary}

Thus, the personality's space may include imagery and semantic content of the two varieties of space: the intimate and personal ones. The features of the intimate space include modeling of the person's inner life - reflection, remembering, emotional experience and peculiarities reflections, remembering, emotions and experiences peculiarities of speech flow. The way of expressing the intimate space in the music becomes the introduction of two types of inner monologue: a monologue-reflection and a monologue-self-reflection. The structure of the intimate space is characterized by closedness, by the reproduction and maintenance of features having the same volume.

The features showing the hero's stay in the personal space in the music include the presence of something unusual, ingenious in the 'behavior' of a musical character. The way of expressing the unusual is a departure from the usual genre, stylistic, thematic and traditional regularities of the musical language of the epoch. Another feature is the presence of the speech beginning expressed in various forms of dialogue aimed at changing the outside world. The third marker of personal space is a high degree of energy message transmitted through the intensity of the experienced emotion directed to the outside world. The fourth marker is thematization of the musical texture layers containing features of various musical characters entered into the personal space of the hero. The structure of the personal space is discrete and depends on the hero's behavior and the events taking place in it. As a rule, the personal space is open, since it incorporates the characteristics of other musical characters, introduced by means of a dramatic intonation contrast, a conflict. All this creates a voluminous, multi-faceted artistic image of a personality's the world in the piece of music.

\section{Conclusion}

Comprehension of the features of personality's space embodiment in the music makes it possible to easily 'discover' social models in the content of the musical genres that are inherent in the way of life and world perception of the person of a certain culture and a certain epoch. 'To unriddle' and 'to guess' a person in a piece of music through the variety of characters and events is one of the exciting and attractive aspects of music. The personality's self-identification and the realization of a musical work as a custodian of the living history of human societies conveyed in musical sound occur through understanding the hero.

\section{References}

Aranovskyy, M.G. (1987). Struktura muzykalnogo zhanra i sovremennaya cituatsiya v muzyke [Structure of a Musical Genre and Modern Situation in the Music//Musykalnyy sovremennik. - Moscow: Sov. kompositor. Iss. 6. (pp. 15-18). [in Russian]

Golubeva, E.A. (2005). Sposobnosti. Lichnost. Individualnost. [Abilities. Personality. Individuality] - Dubna: Feniks+. (P. 682). [in Russian]

Hall, E. (1966). The Hidden Dimension. New York: Doubleday. (P.466).

Hall, E. (1968). Proxemics // Current Anthropology, 9. (p.p. 83-108).

Horney, K. (1997). Nashi vnutrennie konflicty [Our Inner Conflicts] Translated into Russian. - St. Petersburg: Lan. (P.164). [in Russian]

Jung, C. (1996). Chelovek I ego simvoly. [Man and His Symbols]- Moscow: Timoty. (P.352). [in Russian]

Kazantseva, L.P. (2009). Osnovy teorii muzykalnogo soderzhaniya [The Foundations of the Theory of Musical Content] - Astrakhan: Volga. (P.424). [in Russian]

Kholopova, V.N. (2010). Muzykalnye emotsii [Musical Emotions]: Manual. - Moscow: Multiprint. (P.348)c. [in Russian]

Lewin, K. (2001). Dinamicheslaya psikhologiya: izbrannye trudy [Dynamic Psychology: Selected Works] - Moscow: Smysl. (P.572). [in Russian]

Medyshevskyy, V.V. (1976). O zakonomernostyakh i sredstvakh khudozhestvennogo vozdeistviya muzyki [On Regularities and Means of Artistic Impact of Music] - Moscow: Muzyka. (P.254). [in Russian]

Mozgot S. (2013). Personal Space in Music: the "I-the Me" and "I-You" Concepts // TEXT. No. 2. Bruxelles. (pp. 23-31.)

Mozgot, S.A. (2011). Intimnoe prostranstvo v muzyke XVII - XIX vv.: sposoby vyrazheniya i priznaki [The Intimate Space in the music of XVII - XIX c.c.: ways of expression and features] // Bulletin of the Adyghe State University. No. 4 (90). (p.p. 236-243). [in Russian]

Nazaikinskyy, Ye. V. (1972). O psikhologii musykalnogo vospitaniya [ On Psykhology of Musical Education] - Moscow: Muzyka. (P. 368). [in Russian]

Nazaikinskyy, Ye. V. (2003). Stil i zhanr v muzyke [Style and Genre in Music]: Manual. - Moscow: Vlados. (P. 248). [in Russian]

Nemkovskaya, V.I. (1998). Personazh kak kategoriya muzykalnoy poetiki [A Character as a category of Musical Poetics]: Abstract of candidate thesis ... Ph.D. in Art History. -Moscow. (P. 24). [in Russian]

Orlov, G.A. (2005). Drevo musyki [The Tree of Music] - St. Petersburg: Kомпозитор. 440 c. [in Russian]

Osipenko, O.A. (2010). Pretvorenie personazhnykh tem v rannikh kvartetakh D.D. Shostakovicha [Conversion of Personage Themes in the Early Quartets of D.D. Shostakovich] Bulletin of the Adyghe State University. No. 1. (p.p. 144-146). [in Russian] 
Pigaliov, A.I.(2012). Sotsialnoe prostranstvo i kultura: philosophskie aspekty [Social Space and Culture: Philosophical Aspects] // Mir psikhologii. No. 4 (72). (p.p. 30-42). [in Russian]

Potiomkin, V.K. \& Simanov, A.L. (1990). Prostranstvo v structure mira [Space in the Structure of the World] - Novosibirsk: Nauka. (P.174). [in Russian]

Reber, A.S. (2000). Bolshoi tolkovyy psikhologicheskyy slovar [Unabridged psychological dictionary] : In 2 vols. - Moscow: Veche. Vol. 1. (P. 243). [in Russian]

Saiko, E.V. (2012). Prostranstva organizatsii sotsialnoi evolutsii v universume Bytiya i Chelovek v prostranstvennoy Organizatsii Sotsiuma [Spaces of Social Evolution Organization in the Universum of Being and Man in the Spatial Organization of Socium] II Mir psikhologii. No. 4 (72). (p.p. 3-17). [in Russian] 